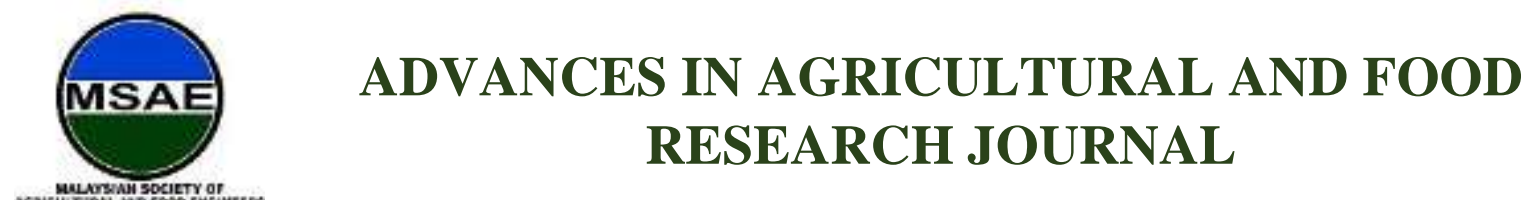

HH PUBLISHER

Original Research Article

\title{
Conceptual Development of Automated Harvester for Tall Oil Palm Tree
}

\author{
Mohd Hudzari Razali ${ }^{*}$, Muhammad Aliuddin Bakar ${ }^{1}$, Muhammad Syukri Mohd Sabir ${ }^{1}$ \\ ${ }^{1}$ Faculty of Plantation and Agrotechnology, Universiti Teknologi MARA, Jasin Campus, 77300, Melaka, \\ Malaysia. \\ *Corresponding author: Mohd Hudzari Razali, Faculty of Plantation and Agrotechnology, Universiti Teknologi \\ MARA, Jasin Campus, 77300, Melaka, Malaysia; hudzari @uitm.edu.my
}

\begin{abstract}
Innovation and invention in field mechanization for oil palm sector has created a variety of advancement in technology. The change in oil palm operation to mechanization will overcome the problem of labour shortage occurrence in oil palm sector. The problem occurs in harvesting tall oil palm is the height of oil palm that causes difficulty to cut the fresh fruit bunch by using manual labour. Moreover, the use of automated harvester also will make the harvesting operation easier without the requirement of skilled labour and ensuring labour safety. The automated harvester has advantages and disadvantages that need to be improved in meeting the oil palm requirement. This study overviews the mechanization that are used in harvesting tall oil palm. This research project has resulted in the development of high technology mechanization based on previously developed machine for harvesting fresh fruit bunches (FFB) at 10 meter and above of oil palm age tress. However, the previous developed machines cannot be accepted in the current and widely practiced Industrial revolution 4.0 (IR4.0). Mechanization approach makes harvesting tall oil palm a reality to overcome the problem that normally occur in oil palm sector due to height of oil palm.
\end{abstract}

Keywords: Dimension; harvesting; labour shortage; mechanization; tall oil palm

Received: $11^{\text {th }}$ November 2020

Citation: Razali MH, Bakar, MA, \& Mohd Sabri, MS.

Accepted: $12^{\text {th }}$ December 2020 Conceptual development of automated harvester for tall oil palm tree. Adv Agri Food Res J 2020; 1(2):

Available Online: $20^{\text {th }}$ December 2020 a0000151. https://doi.org/10.36877/aafrj.a0000151

\section{Introduction}

Malaysia is the one of the world's largest producers and exporters of oil palm after Indonesia. According to Kamil et al. (2017), palm oil in Malaysia is mostly exported to other countries such as India, China, European Union, Pakistan, Egypt and Bangladesh. In 2015, 25.37 tonnes of oil palm products were exported Malaysia to other countries (MPOB, 2016). Milling is a crucial process to extract the crude palm oil from the fruit mesocarp. It also involves the initial detachment of the individual fruit from its bunch. The milling process 
starts with the bunch reception, and continues with sterilization, threshing, digestion, pressing, clarification and purification. Initially, the FFB including the loose fruits are fed into the sterilizer cages through the hopper. Good management in oil palm plantation, such as in detecting unhealthy plants, fertilization plan, processing plan and irrigation management, is very important as Malaysia is the largest producer (Carolita et al., 2015). Therefore, harvesting and collection of oil palm requires a skill to cut the fresh fruit bunch from bunch stalk and for 3D perception of this job, dangerous, dirty and difficult that resulted in minimal involvement of the locals and increased avenues for foreign workers to work in plantation sector (Ismail, 2013). The characteristic of oil palm usually can grow up to $15 \mathrm{~m}$ high depends on the varieties or species of the oil palm. The height may cause harvesting problem and difficulties in manual harvesting requiring labor intensity and skillful labor. This situation has also affected the supply of palm oil in the domestic as well as world markets (Ismail, 2013).

There are around $60 \%$ of the total work operation in harvesting fresh fruit bunches (FFB) and $50 \%$ of total workers in the production cost (Sowat et al., 2018). The harvesting of tall oil palm tends to be difficult due to height of oil palm trees and the space of frond within fruit bunches that cannot be seen by the harvesters beneath and far from the focus point level of the eyes. Furthermore, for tall palms (greater than 2.5 metres height), a sickle attached to a long pole is used. The sharpness, shape and profile of the sickle contribute to the effectiveness of the cutting operations through pulling the sickle downwards. Energy for cutting comes mainly from the harvester testing on his endurance and it can be reduced by the tool sharpness and self-skill such as lifting, and handling the long pole, and cutting the fronds as well as fruit bunches. Hence, this would result in low productivity of the skillful labor and harvesting can be up to 2:00 pm in the evening (Jelani, 1997; Jelani et al., 2008). Sharence et al. (2018) stated that to alleviate issues surrounding the human workforce such as labor shortage and injuries, the proposed climbing robots can be deployed to replace these workers. In addition, climbing robots are smaller than harvesting machines and therefore they are not plagued by problems associated with operating huge machinery in the farm.

The study on harvesting cutter used in the mechanical harvesting was conducted at the Malaysian Palm Oil Board (MPOB). Oil palm industry Malaysia was entrusted serve by MPOB and become one of the most premier government agencies under the Ministry of Plantation Industries and Commodities The roles of MPOB are to promote and develop policies, objective and priorities that are created by national government as well as to make sure the oil palm industry is well managed and controlled by the national government. The effective service and international focus in oil palm industry that have more than 20 years was responsible by MPOB to provide best services in oil palm industry (Palm Oil World, 2019). 
Based on the main geometric concept of common normal between two lines, Denavit and Hartenberg (1995) introduced a conventional technique for selecting joints of reference in robotics application that used homogeneous transformation and represented minimally as product of four basic transformations. Denavit and Hartenberg (D-H) representation has become the standard way of representing robots and modeling their motions (Denavit and Hartenberg, 1995). The method begins with a systematic approach in assigning and labeling an orthonormal $(\mathrm{x}, \mathrm{y}, \mathrm{z})$ coordinate system to each robot joint. It is then possible to relate one joint to the next and ultimately to assemble a complete representation of a robot's geometry. D-H convention was mainly implemented in robot manipulators, which consist of an open kinematic chain in which each joint contains one DOF with either revolute or prismatic joint. The transformation was described by the following four parameters known as D-H parameters, which are a is length, $\alpha$ is twist, $d$ is twist and $\theta$ is angle.

Bouketir (1999) has developed a vision-based interface for a three degree of freedom (DOF) agricultural robot that involved the D-H approach. Experiments were carried out for the robot to grab the target, which was a red fruit bunches with the help of vision (Charge Couple Device camera) and back to the home position. While Razali (2003) has developed the system able to retrieve real time dynamic video scene and from there the three coordinate axes of object target and generated using mouse click action. The coordinates were calculated using triangulation principle based on the video scene of two different locations of cameras. These 3-axis coordinates were measured from the Cartesian robot coordinate that was taken as reference point to calculate a mathematical model for robot simulation and kinematics. The workspace in the simulation software was calibrated to be the same with real robot workspace.

\section{Materials and Methods}

\subsection{Location of Study Area}

The study and data collection were conducted on harvesting cutter available at Malaysian Palm Oil Board (MPOB), Bangi.

This study utilized a descriptive analysis approach. The data has been collected, summarized and compared in the simplest way. Qualitative method was used for the case study in measurement, simple calculation and dimension method.

\subsection{Parameters of Mechanization}

The dimension of the object is required to make a topological measurement size of the object in covering the properties and coordinate to specify the point of the object. There are two types of dimensions such as rectangle in two-dimensional or cube in threedimensional. The dimension of an object also called as "dimensionality", was required to 
study and use in calculation because it provides the parametrization for the conceptual or visual complexity (Eric, 2017).

The comparison of several types of tractors or harvesters used in harvesting tall oil palm based on operated mechanization were conducted in this study: (1) track, (2) wheel, (3) half-track. The advantages and disadvantages were evaluated on which mechanization brings more benefit when operated in the field. The findings from comparison and evaluation of mechanization will be used for future benefits. Economic analysis was conducted by calculating the cost mechanization usage in harvesting oil palm. It included the following factors: (1) machine price; (2) economic life; (3) productivity; (4) total cost; (5) effective field capacity.

\section{Results and Discussions}

\subsection{Parameter of Machines}

Figure 1 shows the dimension of half-track mechanization from the side view of the dimension: (a) driver seat, (b) hydraulic power steering, (c) hydraulic oil tank, (d) bucket, (e) stabilizer, (f) hydraulic telescopic boom, (g) vertical telescopic boom, (h) claw cutter; (i) grapple. The important parts use for harvesting process are the hydraulic telescopic boom, claw cutter, grapple and bucket. The function of hydraulic telescopic boom is used to extend the boom to achieve suitable length to cut the FFB. Claw cutter is used to cut the FFB from the stalk and to cut the frond of the oil palm. The grapple is used to hold the oil palm fruit bunch after the cutting process and transfer of FFB to the bucket. The use of grapple is important to avoid the damage of FFB due to fall from the high elevation to the ground and to preserve the quality of the FFB. The bucket is used as a storage of FFB throughout harvesting and collecting of FFB. The track system in the movement of machine signifies the difference from this half-track mechanization to track and wheel type.

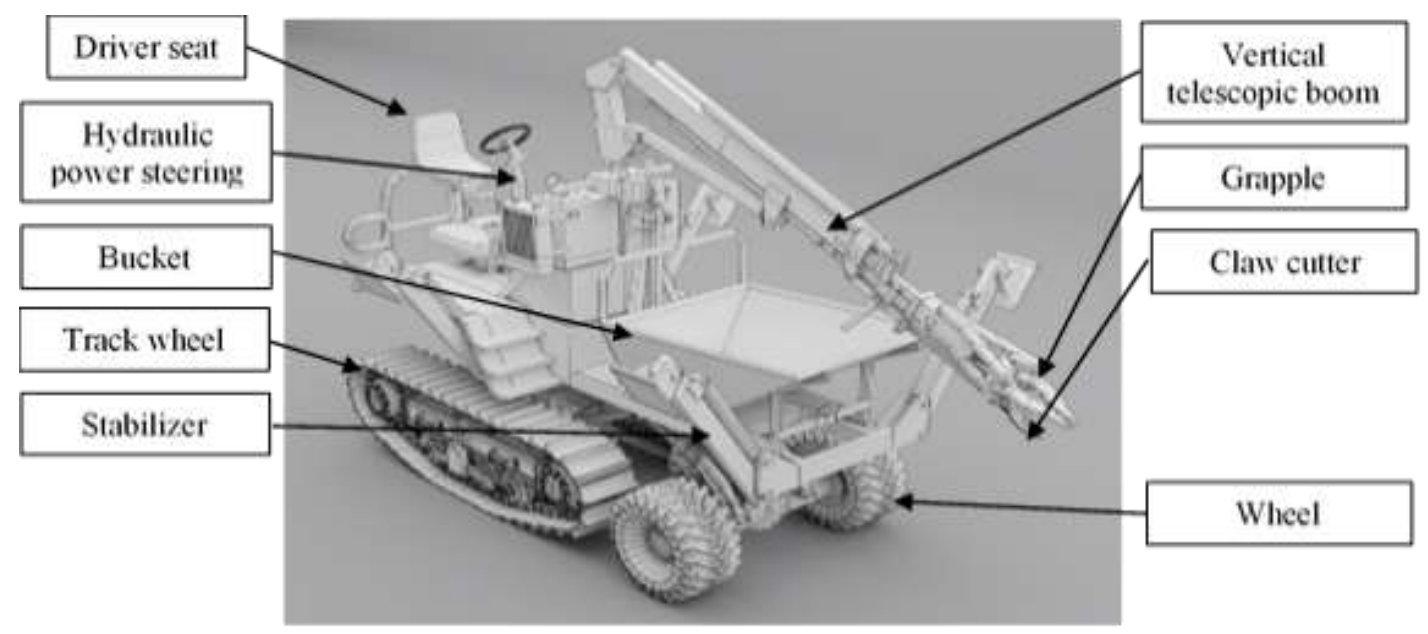

Figure 1. Side view dimension for half-track mechanization. 


\subsection{Motion Study for Harvesting Activities}

Table 1 shows that the track type mechanization carried out the longest time to carry out harvesting activities in $112 \mathrm{sec}$ from reaching the bunch, cutting, reacting and bringing FBB to bin and moving the machine to the next oil palm tree and resume its cutting activities. The wheel type contributed to moderate time taken to carry out complete cycle of harvesting activities in $103 \mathrm{sec}$. The half-track type shows the least time taken to carry out harvesting activities in $98 \mathrm{sec}$. This shows that the track type has poor performance in harvesting oil palm that need higher time to complete one cycle. Half-track type shows the best performance in harvesting process among the mechanization available in MPOB.

Table 1. Average time taken to carry out harvesting activities.

\begin{tabular}{cccc}
\hline Movement/activity & $\begin{array}{c}\text { Average time taken } \\
\text { for track type }(\mathrm{sec})\end{array}$ & $\begin{array}{c}\text { Average time taken } \\
\text { wheel type (sec) }\end{array}$ & $\begin{array}{c}\text { Average time taken } \\
\text { half-track type (sec) }\end{array}$ \\
\hline $\begin{array}{c}\text { Telescopic boom extends until } \\
\text { reaching the bunch } \\
\text { Cutting process }\end{array}$ & 12 & 35 & 34 \\
$\begin{array}{c}\text { Telescopic booms react and } \\
\text { bringing FFB to bin }\end{array}$ & 34 & 26 & 26 \\
$\begin{array}{c}\text { Machine move to the next palm } \\
\text { and resume its cutting activities }\end{array}$ & 38 & 34 & 30 \\
Total & 112 & 103 & 98 \\
\hline
\end{tabular}

Table 2 shows that track type mechanization resulted to slow speed of movement of machine to the field with the maximum average speed of $10 \mathrm{~km} / \mathrm{h}$ and $3 \mathrm{~km} / \mathrm{h}$ to complete one cycle of harvesting process before resuming to the next. Wheel type exhibited moderate speed of movement of machine to the field at $15 \mathrm{~km} / \mathrm{h}$ maximum speed and $5 \mathrm{~km} / \mathrm{h}$ to complete one cycle of harvesting process. The half-track type the best performance by ranking as the highest speed of movement of machine to the field. This shows that track type has the poorest performance in speed of movement mechanization because of the type of movement that used is track system. Average speed of mechanization moving from one palm tree to another affected the productivity of the mechanization when used in the field. However, the wheel type shows better performance than track type, which moved to the field with speed higher than track type. Integration of track type and wheel type mechanization would bring more efficiency in speed travel when used in the field in the form of half-track type. Speed of movement is important to make sure the mechanization is suitable with the topography of the oil palm field interacting with the mode of movement used that impacted the productivity of operation. 
Table 2. Speed of movement of machine to the field.

\begin{tabular}{cccc}
\hline Movement/activity & $\begin{array}{c}\text { Average speed for } \\
\text { track type }(\mathrm{km} / \mathrm{h})\end{array}$ & $\begin{array}{c}\text { Average speed wheel } \\
\text { type }(\mathrm{km} / \mathrm{h})\end{array}$ & $\begin{array}{c}\text { Average speed half- } \\
\text { track type }(\mathrm{km} / \mathrm{h})\end{array}$ \\
\hline $\begin{array}{c}\text { Maximum speed } \\
\text { Minimum speed }\end{array}$ & 10 & 15 & 20 \\
$\begin{array}{c}\text { Machine move to the next } \\
\text { palm and resume its cutting } \\
\text { activities }\end{array}$ & 5 & 5 & $8-10$ \\
\hline
\end{tabular}

\subsection{Economic Analysis of Mechanization Types Used in FBB Harvesting}

Table 3. Economic analysis of mechanization types used in FFB harvesting.

\begin{tabular}{|c|c|c|c|}
\hline Particular & Track type system & Wheel type system & Half-track system \\
\hline Machine price & RM 140000 & RM 160000 & RM 18000 \\
\hline Economic life & 6 years & 6 years & 6 years \\
\hline Productivity & $250 \mathrm{FFB} / 6$ tonnes days & $300 \mathrm{FFB} / 8$ tonnes days & 350 FFB / 10 tonnes days \\
\hline Labour cost & $\begin{array}{c}(\mathrm{RM} 0.24 \times 250 \mathrm{FFB})= \\
\mathrm{RM} 60 \text { days }\end{array}$ & $\begin{array}{c}(\mathrm{RM} 0.24 \times 300 \mathrm{FFB})= \\
\text { RM } 72 \text { days }\end{array}$ & $\begin{array}{c}(\mathrm{RM} 0.24 \times 350 \mathrm{FFB})= \\
\mathrm{RM} 84 \text { days }\end{array}$ \\
\hline Working days & 25 & 25 & 25 \\
\hline Fuel consumption & $\begin{array}{c}(18 \text { 1/day x RM } 1.80) \\
\text { = RM } 32.40\end{array}$ & $\begin{array}{c}(15 \text { 1/day x RM 1.80) } \\
\text { = RM } 27.00\end{array}$ & $\begin{array}{c}\text { (17 1/day x RM 1.80) } \\
\text { = RM } 30.60\end{array}$ \\
\hline $\begin{array}{l}\text { Lubricants }(15 \% \\
\text { from fuel cost) }\end{array}$ & $\mathrm{RM} 4.86$ & RM 4.05 & RM 4.59 \\
\hline $\begin{array}{c}\text { Repair and } \\
\text { maintenance cost }\end{array}$ & RM 60 & RM 60 & RM 60 \\
\hline Total cost & RM 277.26 & RM 231.05 & RM 255.19 \\
\hline
\end{tabular}

Table 3 shows that the track type mechanization totaled up to the highest cost of harvesting. The wheel type has lowest total cost of harvesting activities and followed by halftrack type shows high total cost of harvesting, but lower than track type. This shows that track type has higher total cost because the price of machine is higher because of track system usage. The wheel type has moderate total cost because of wheel system usage and will gain higher productivity based on FFB output. However, in meeting the objective of the study in solving the labour shortage and increase in productivity, half-track system shows the best productivity of $350 \mathrm{FFB} / 10$ tonnes collected in 25 given days. With the half-track system, 
there shall be no more issues on labour shortage and low productivity in oil palm harvesting and collection.

\subsection{D-H Parameters Representation of Harvester}

The transformation between two successive joints was written by substituting the D$\mathrm{H}$ parameters from Table 4 into the $A$ matrix. The $\theta$ and d were the joint variables for revolute joints and prismatic joints, respectively with $C 1$ as $\cos \theta 1$ and $S 1$ as $\sin \theta 1$ designation.

Table 4. D-H parameters representation of harvester.

\begin{tabular}{|c|c|c|c|c|}
\hline Joint & $\theta$ (Link angle) & $D$ (Link Offset) & $a$ (Link Joint) & $\alpha($ Link Twist $)$ \\
\hline $1(z 0-z 1)$ & $\theta 1$ & 0 & 0 & 90 \\
\hline $2(z 1-z 2)$ & 0 & $d 2$ & $a 1$ & 90 \\
\hline $3(z 2-z 3)$ & $\theta 3$ & 0 & $a 2$ & 90 \\
\hline $4(z 3-z 4)$ & $\theta 4$ & 0 & 0 & 0 \\
\hline $5(z 4-z 5)$ & 0 & $d 5$ & 0 & 0 \\
\hline
\end{tabular}

Figure 7 show the image and schematic diagram of the harvester manipulator used to cut and harvest the oil palm FFB that currently located at MOPB, Bangi Lama, Selangor. Helena and Wan Ishak (2010) mentioned that the harvester has five DOF, where the first joint 1 was between link 0 (the fixed base) and link $1(z 0-z 1)$, joint $2(z 1-z 2)$ between link1 and 2 , and so on.
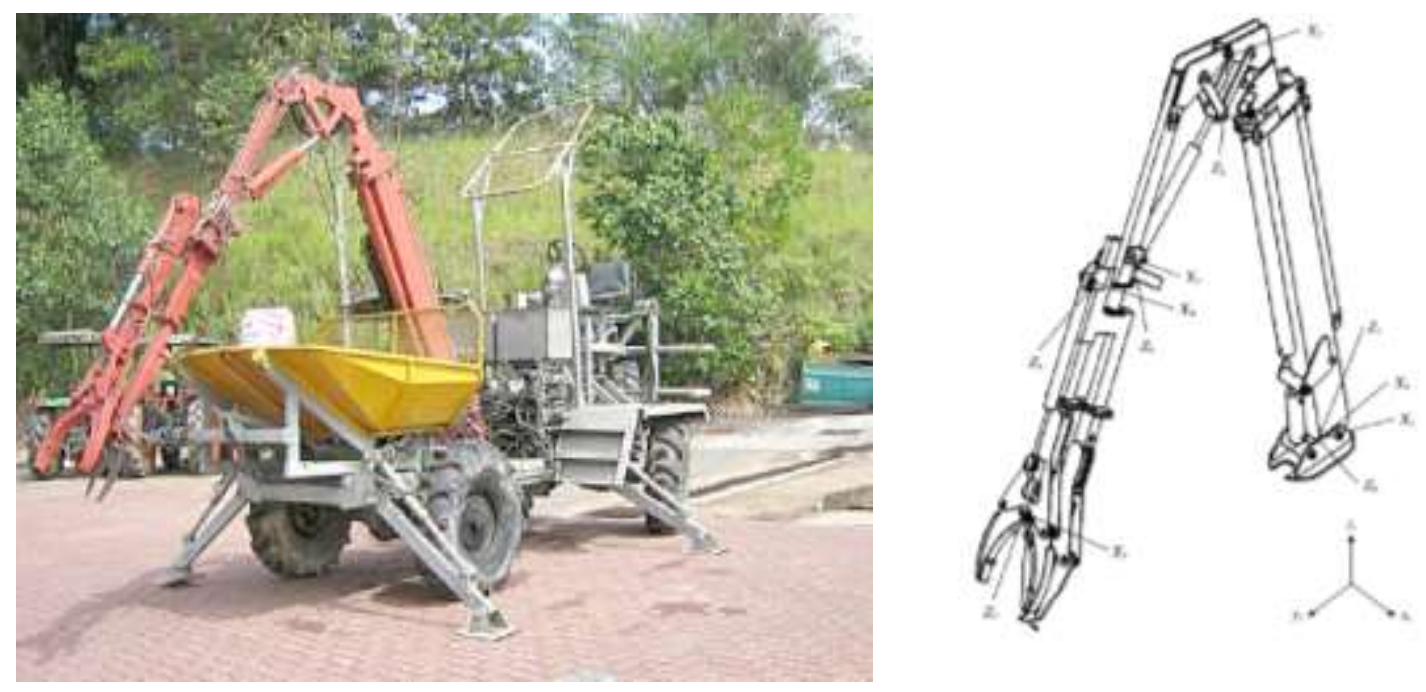

Figure 2. Image and schematic diagram of the harvester manipulator for tall oil palm tress.

Wan Ishak et al. (2011) mentioned that present work of agricultural robotic studies in Universiti Putra Malaysia could be considered as initial research in developing of an 
intelligent robot eye for agriculture harvester robot. By using the concept of non- contact measurement like video-grammetry to detect the object and measure it in 3D coordinate, the development of the robot eye was explored (Razali, 2003). For further research, the robot eye must use the RGB camera, which will be automatically recognizing the mature object by pattern or by color or wave character manipulation without human intervention by clicking the target image. By using the concept of non-contact measurement like video-grammetry for the measurement and detection of coordinate of the target object, the developments of the "robot eye" were explored in agriculture sector. Camera vision recognizes the fruit maturity through forced learning concept. This concept means that the matured fruit to be harvested will be attached at placement on harvester arm if it is done manually. However, camera vision applied the current value of hue digital image of oil palm outdoor and on the field. The programmed system compares the hue value between this trained or dummy output, which can be represented as the benchmark for the input of targeted maturity fruit in reality. In outdoor condition, the vision system will be influenced by illumination changes by sunlight, temperature of environment and humidity on surface target color itself. After the vision system recognized the matured fruit, the system controller proceeds and performed the kinematic calculation for transforming the movement harvester arm automatically through auto pilot concept that had been done by Jayaselan and Wan Ismail (2010). The user shall be assisted by the arm harvester during initial fruit recognition, then when the fruit is recognized through the vision system, then this auto pilot activation took place for machine operation until the harvester automated with gripping and cutting process. This pilot operation includes loading process of fruit into the bin. SCADA system and Arduino components were integrated into the automation part. ERDAS software of GIS were used to retract the information of targeted for mapping process system. The concept of this integration system between D-H conversions, videogrammetry, and outdoor vision recognition were required for development of tall oil palm trees harvester.

\section{Conclusion}

There is no mechanization for harvesting has been applied on the field, except the use of motorized cutter for oil palm trees less than five meters height. However, other sectors in the oil palm industry have utilized mechanization in the processing of the output of oil palm production. Various technologies have been developed by MPOB as well as its contribution to the industry from oil palm harvesting to production of the FFB until the end process to the mill. The importance of producing machine to suit the terrains on Malaysian land is the major limitation for designer to develop appropriate design to overcome the problem that normally occur in oil palm sector due to mechanization usage. Strategic plan is crucial to choose the suitable mechanization with the good specification of mechanization, well-planned dimension or design to fulfil the requirements for mechanization to promote easy access and user-friendly to reduce labour shortage and encourage more skilled workers to be involved in the well paid 3D job (i.e. dangerous, dirty and difficult) of the oil palm sector The employed workers or labours are required to undergo training to learn the mechanism of the 
mechanization type and handling the machine safely and efficiently during harvesting and collection of FFB.

Acknowledgments: The researchers would like to thank the staffs of Malaysia Palm Oil Board, Bangi, Selangor for their assistance.

Funding: This research was supported internally by Faculty of Plantation and Agrotechnology, UiTM, Melaka, Malaysia

Conflicts of Interest: The authors declare no conflict of interest, and also the funders had no role in the design of the study; in the collection, analyses, or interpretation of data; in the writing of the manuscript, or in the decision to publish the results.

\section{References}

Bouketir, O. (1999). Design and development of a vision system interface for three degree of freedom agricultural robot. Master Thesis, Universiti of Putra Malaysia.

Carolita, I., Sitorus, J., Manalu, J., et al. (2015). Growth profile analysis of oil palm by using spot 6 the case of north sumatra. International Journal of Remote Sensing and Earth Sciences, 12(1), 21-26.

Denavit, J., \& Hartenberg, R. S. (1995). A kinematic notation for lower-pair mechanisms based on matrices. Journal of Applied Mechanics, (23): 215-221.

Eric, W. (2017, March 13). Dimension. Retrieved from Wolfarm Mathworld. http://mathworld.wolfram.com/Dimension.html

Helena, A, J, J., \& Wan Ismail, W. I. (2010). Kinematics analysis for five DOF fresh fruit bunch harvester. International Journal of Agricultural and Biological Engineering, 3(3), 1-7.

Ismail, A. (2013). The effect of labour shortage in the supply and demand of palm oil in Malaysia. Oil Palm Industry Economic Journal, 13(2), 15-26.

Jelani, A, R. (1997). Design and development of an oil palm fresh fruit bunch cutting device [Master Thesis]. University of Putra Malaysia.

Jelani, A, R., Hitam, A., Jamak, J., Noor, M., et al. (2008). Cantas TM - A Tool for the efficient harvesting of oil palm fresh fruit bunches. Journal of Oil Palm Research, (20): 548-558.

Kamil, N. N., Balu, N., Ismail, N., et al. (2017). An analysis of malaysian palm oil exports to selected TPPA member countries. Oil Palm Industry Economic Journal, 17(2), 34-43.

Malaysian Palm Oil Board (2016, February 23). Overview of the Malaysian oil palm industry 2015. Retrieved from: http://bepi.mpob.gov.my/images/overview/Overview_of_Industry_2015.pdf.

Palm Oil World. (2019). About the Malaysian Palm Oil Board. Retrieved on April 22, 2019, from http://www.palmoilworld.org/about_mpob.html

Razali, M. H. (2003). Videogrammetry technique for arm positioning of bio-production robot. Master Thesis, Universiti Putra Malaysia.

Sowat, S. N., Wan Ismail, W. I., Mahadi, M. R., et al. (2018). Trend in The Development of Oil Palm Fruit Harvesting Technologies in Malaysia. Jurnal Teknologi (Sciences \& Engineering), 80(2), 83-91.

Wan Ishak, W. I., Hudzari, R. M., Nasir, S. M., et al. (2011). Videogrammetry application for stereo vision bio- 
production harvester. Trends in Applied Sciences Research, 6(5), 495-506.

CC (7) \$ Copyright $\odot 2020$ by Razali MH, et al. and HH Publisher. This work is licensed under the Creative Commons cC) Attribution-NonCommercial 4.0 International Lisence (CC-BY-NC4.0) 